\title{
Detección de micrometástasis en médula ósea de pacientes con cáncer de vesícula biliar
}

\author{
Juan C Roa $S^{1}$, Xabier de Aretxabala $U^{\mathbf{2}}$, Angélica Melo $A^{\mathbf{1}}$, \\ Gaspar Faría ${ }^{2}$, Juan $C$ Araya $\mathbf{O}^{1}$, Miguel A Villaseca $\mathbf{H}^{\mathbf{1}}$, \\ Pablo Guzmán G1', Iván Roa E¹. \\ Detection of bone marrow \\ micrometastases in patients with \\ gallbladder cancer
}

\begin{abstract}
Background: There is a very strong documented correlation between the appearance of cancer cells in blood and occurrence of metastasis in gastrointestinal cancer. Aim: To determine MUC1, CK19, CK20 and CEA mRNA expression in bone marrow of patients with gallbladder cancer and evaluate its clinical significance. Material and methods: Sixty eight samples were analyzed, 38 bone marrow samples of gallbladder cancer patients, 20 healthy donors, and 10 frozen samples of gallbladder cancer. Nested reverse transcriptase-polymerase chain reaction (nested RT-PCR) was used to analyze mRNA expression. Results: All frozen tumors were positive for CEA, CK19, and MUC1 mRNA and 70\% were positive for CK20. Seventeen of 20 donor samples were positive for MUC1 and only one sample from donors was positive for both CK20 and CK19 mRNA. Among the 38 blood and bone marrow samples of gallbladder cancer patients, the expression of MUC1, CK19, CK20, and CEA, mRNA was $60.5 \%$ (23/38), 31.6\% (12/38), 7.9\% (3/38), and 7.9\% (3/38), respectively. Disregarding the MUC1 results. 37\% (14/38), 13\% (5/38) and 5\% (2/38) were positive for one, two and three markers respectively. Not significant differences were found in survival with a follow up to 12 months. Conclusion: Our results indicate that the molecular detection of tumor cells in bone marrow in patients with gallbladder carcinoma is technically possible, being CEA, CK19 and CK20 gene expression the best markers. The MUC1 gene expression marker was highly unspecific and it should not been considered. The detection of bone marrow micrometastasis might be helpful in prognosis and the selection of clinical treatment but a larger series with a longer follow-up should be studied (Rev Méd Chile 2004; 132: 1489-98).
\end{abstract}

(Key Words: Carcinoembryonic antigen; Gallbladder neoplasms; MUC1 gene product; Neoplasm metastasis)

Recibido el 9 de marzo, 2004. Aceptado en versión corregida el 7 de octubre, 2004. Trabajo financiado por proyecto Fondecyt \# 1010253.

${ }^{1}$ Departamentos de Anatomía Patológica y de ${ }^{2}$ Cirugía y Traumatología, Universidad de La Frontera, Temuco, Chile.

Correspondencia a: Dr. Juan Carlos Roa. Departamento de Patología, Facultad de Medicina, Universidad de La Frontera. Manuel Montt 112. Código Postal 478-1176. Temuco, Chile. E-mail: jcroa@ufro.cl 
$\mathrm{E}^{1}$ cáncer de vesícula biliar es muy común en Chile, siendo la primera causa de muerte por cáncer en mujeres sobre los 40 años. A pesar de los avances del tratamiento del cáncer gastrointestinal el pronóstico de éstos y de los carcinomas avanzados de vesícula biliar, en particular, es aún muy malo ${ }^{1,2}$.

Los modelos de metástasis indican que las células tumorales se extienden desde los tumores primarios vía la circulación (sangre y vasos linfáticos) a otros órganos, y por invasión local hacia el hígado y hacia los órganos vecinos. Por tanto, parece ser que existe una muy fuerte asociación entre la aparición de células tumorales en la sangre y el desarrollo de metástasis.

Actualmente la extensión hematógena de los cánceres sólidos representa una de las principales fallas del tratamiento oncológico. Con el mejoramiento de las técnicas diagnósticas se han introducido métodos de biología molecular para identificar el proceso con mayor exactitud y sensibilidad. Las células tumorales pueden diseminarse hacia la circulación aun en las primeras etapas del tumor ${ }^{3}$. Sin embargo, el número de tales células es muy pequeño y ellas no pueden ser detectadas por métodos diagnósticos convencionales tales como los estudios de imágenes o test de marcadores serológicos ${ }^{4}$.

La amplificación en cadena mediada por la polimerasa (PCR) puede detectar marcadores celulares que se expresan específicamente en estas células y que son indetectables por otros medios en los pacientes con cáncer metastásico o con enfermedad localizada. Dos diferentes estrategias han sido usadas para detectar las células tumorales diseminadas en la circulación o en la médula ósea ${ }^{5,6}$. La primera corresponde a blancos en la secuencia del $A D N$, esto se refiere fundamentalmente a alteraciones genómicas tales como mutaciones específicas en oncogenes, análisis de microsatélites y amplificación génica. La segunda, al análisis en las alteraciones en la secuencia de ARN, básicamente referido a transcriptos específicos de ARN mensajero en las células tumorales y de cada tejido en particular. Para estos análisis se requiere de una reacción de transcripción reversa que transforma el ARN a ADNc y luego lo amplifica en forma regular, lo que se conoce como RT-PCR. En este sentido varias reacciones de RT-PCR han sido descritas para el antígeno carcino-embrionario (CEA), la citoqueratina 19 (CK19) y la citoqueratina 20 (CK20) para la detección de células circulantes de cáncer colorrectal y cáncer gástrico ${ }^{3,7}$; mamaglobina para los cánceres de mama ${ }^{8,9}$, MAGEs para melanoma10, mutación de K-ras para cánceres pancreáticos y de colón ${ }^{11,12}$, antígeno prostático específico (PSA) para cánceres de mama y de próstata13,14. De esta manera el RT-PCR está ofreciendo una significativa promesa de mejorar la detección de enfermedad residual mínima en la circulación periférica, médula ósea y ganglios linfáticos.

Las micrometástasis en médula ósea están presentes en sobre un cuarto de los pacientes que son sometidos a resecciones curativas por cáncer gastrointestinal ${ }^{4}$. En relación a su validez como factor pronóstico, las micrometástasis en los ganglios linfáticos están asociados con una significativa reducción en la sobrevida a 5 años de los pacientes en estadio II con cáncer colorrectal, especialmente interesante, si consideramos los pacientes en el grupo III de Dukes, los cuales no muestran metástasis ganglionares linfáticas en las secciones rutinarias teñidas con hematoxilina y eosina ${ }^{15}$. En otros estudios, la detección de micrometástasis en aspirados de médula ósea ha demostrado utilidad como un predictor de mal pronóstico en pacientes con cáncer bronquial no células pequeñas ${ }^{16,17}$. Los pacientes con micrometástasis en médula ósea o con células circulantes tumorales en sangre periférica son comparables a pacientes con metástasis, en términos de la localización del tumor primario, patrón de recidiva y pronóstico de la enfermedad ${ }^{16,18-20}$.

Esta evidencia sugiere que una etapificación más precisa basada en el diagnóstico de las micrometástasis de médula ósea mediante RT PCR puede ser un mejor predictor de la recurrencia y de la sobrevida a corto plazo, que el método histológico convencional, con tinción de hematoxilina y eosina y puede servir como un criterio para tomar decisiones clínicas.

Las muestras de médula ósea o de sangre periférica, que se obtienen antes de la manipulación quirúrgica de los tumores primarios, ofrece el mejor indicador de diseminación sistémica de la enfermedad. Sin embargo, en la mayoría de los cánceres de vesícula biliar, los pacientes en etapas iniciales son diagnosticados sólo después del estudio de la pieza quirúrgica de la colecistecto- 
mía. Usualmente la etapificación de estos pacientes son completados con un mapeo total de la muestra quirúrgica y en pacientes con formas potencialmente curativas (invasión restringida a la pared vesicular hasta en la subserosa) se realiza una segunda cirugía con disección ganglionar selectiva más resección hepática parcial ${ }^{21}$.

Este estudio fue diseñado para desarrollar un método sensible para la detección de micrometástasis en médula ósea en pacientes con cáncer de vesícula biliar mediante la técnica de RT-PCR. Estudiamos la expresión de CEA, CK19, CK20 y Mucina sialada 1 (MUC1) en médula ósea y exploramos la asociación entre los 4 genes con algunas características clínico-patológicas y sobrevida de los pacientes con carcinoma de la vesícula biliar.

\section{PACIENTES Y MÉTODOS}

Estudiamos 68 muestras correspondientes a 38 muestras de médula ósea de pacientes colecistectomizados con diagnóstico de carcinoma de la vesícula biliar, 20 muestras de donantes aparentemente sanos desde el Banco de Sangre, pareados por sexo y edad con los casos estudiados y 10 muestras de tumores frescos congelados de vesícula biliar, provenientes de los archivos del Departamento de Anatomía Patológica, de la Universidad de La Frontera y del Servicio de Anatomía Patológica y Citopatología del Hospital Regional de Temuco, entre junio de 2002 y julio de 2003.

Sólo 2 pacientes recibieron quimioterapia con gemcitabina antes que la muestra haya sido tomada. Se obtuvo consentimiento informado en cada paciente. La etapa TNM clínico patológica fue determinada de acuerdo a la regulación de la UICC $(1997)^{22}$.

Los aspirados de médula ósea de los pacientes y las muestras de los donantes fueron procesados antes de 4 horas desde el momento de su obtención. Los leucocitos fueron aislados por una gradiente de centrifugación usando Linphoprep (Nycomed Pharma Norway) de acuerdo al protocolo sugerido por los fabricantes y luego fueron almacenados en tiocianato de guanidina a una temperatura de $-75^{\circ} \mathrm{C}$ hasta el momento de la extracción del ARN.
Los tejidos de tumores vesiculares fueron también obtenidos y almacenados en tubos con gel criopreservante (Jung, Alemania) a una temperatura de $-75^{\circ} \mathrm{C}$ antes de proceder a la extracción de ARN.

Extracción ARN. La extracción total de ARN de leucocitos concentrados fue desarrollada de acuerdo al método Chomczyski ${ }^{23}$. Para los tejidos se utilizó el reactivo de crisol (Life Technology USA) de acuerdo a instrucciones de los fabricantes. Después de la precipitación de ARN éste fue resuspendido en $10 \mu \mathrm{l}$ de agua tratada con Dietilipirocarbonato (DEPC) y luego almacenada a $-80^{\circ} \mathrm{C}$.

La cuantificación del ARN fue determinada por un espectofotómetro Genequant (Amersham US). Para asegurar la ausencia de contaminación de $\mathrm{ADN}$ en las muestras de ARN fueron tratadas con RQ1 DNasa (Promega, USA) por 30 minutos a $37^{\circ} \mathrm{C}$.

Reacción de la transcripción reversa (RT). Fueron usados dos microgramos de ARN como templados en la primera hebra complementaria del ADN (ADNc) síntesis en $20 \mu \mathrm{l}$ de volumen de reacción el cual consistió en random primer (3,75 micromoles por reacción), dNTP $(0,5 \mathrm{mM} /$ por reacción), enzima M-MVL (Invitrogen USA) 200 unidades por reacción. El ARN fue incubado a $60^{\circ}$ por $5 \mathrm{~min}$, después de la mezcla de la reacción, incubado luego a $20^{\circ} \mathrm{C}$ por $5 \mathrm{~min}$, ya $37^{\circ}$ por 50 min, seguido por una incubación a $5^{\circ} \mathrm{C}$ por $5 \mathrm{~min}$.

Detección de expresión génica mediante PCR. Las condiciones de amplificación así como la secuencia de los iniciadores primers, 24,25 se encuentran en la Tabla 1. Para verificar la integridad y pureza del ARN se realizó un PCR simple para el gen $\mathrm{DRB} 1$, que permite detectar la presencia de ADN no proveniente de la reacción de transcripción reversa. Básicamente se utilizó 5 a $10 \mathrm{ng}$ de ADN complementario, y concentraciones de $0,2 \mathrm{mM}$ nucleótidos y de 1,5 mM de cloruro de magnesio, adicionando 0,6 $\mathrm{U}$ de taq ADN de polymerasa (Promega) por reacción, en un volumen total de $15 \mu \mathrm{l}$. Los productos finales fueron analizados mediante electroforesis en geles de agarosa al $2 \%$.

Estadística. Se calcularon sensibilidad y especificidad de la expresión de cada uno de los genes de estudio 
Tabla 1. Listado de los iniciadores tamaño de los productos y las condiciones de PCR usados en este estudio

\begin{tabular}{|c|c|c|c|}
\hline Nombre & Secuencia 5'-3' & Tamaño $(\mathrm{Pb})$ & Condiciones de PCR \\
\hline CK-19 A & aggtggattccgctccgggca & 461 & 35 ciclos, $\mathrm{T}^{\circ}$ Hibridación $60^{\circ} \mathrm{C} \mathrm{MgCl} 1,5 \mathrm{mM}$ \\
\hline CK-19 R & tgctcgagggacaggaagat & & \\
\hline CK-20 A & cagacacacggtgaactatgg & 370 & 40 ciclos $\mathrm{T}^{\circ}$ Hibridación $55^{\circ} \mathrm{C} \mathrm{MgCl}$ 1,5 mM \\
\hline CK-20 R & gatcagcttccactgttagacg & & \\
\hline CEA A & tctggaacttctcctggtctctcagctgg & 160 & 40 ciclos $\mathrm{T}^{\circ}$ Hibridación $60^{\circ} \mathrm{C} \mathrm{MgCl} 2,0 \mathrm{mM}$ \\
\hline CEA R & tgtagctgttgcaaatgctttaaggaagaagc & & \\
\hline MUC1 A & cgtcgtggacattgatggtacc & 288 & 35 ciclos, $\mathrm{T}^{\circ}$ Hibridación $60-64^{\circ} \mathrm{C} \mathrm{MgCl} 2,0 \mathrm{mM}$ \\
\hline MUC1 R & ggtacctcctctcacctcctccaa & & \\
\hline
\end{tabular}

$\mathrm{A}=$ anterógrado $\mathrm{R}=$ retrógrado

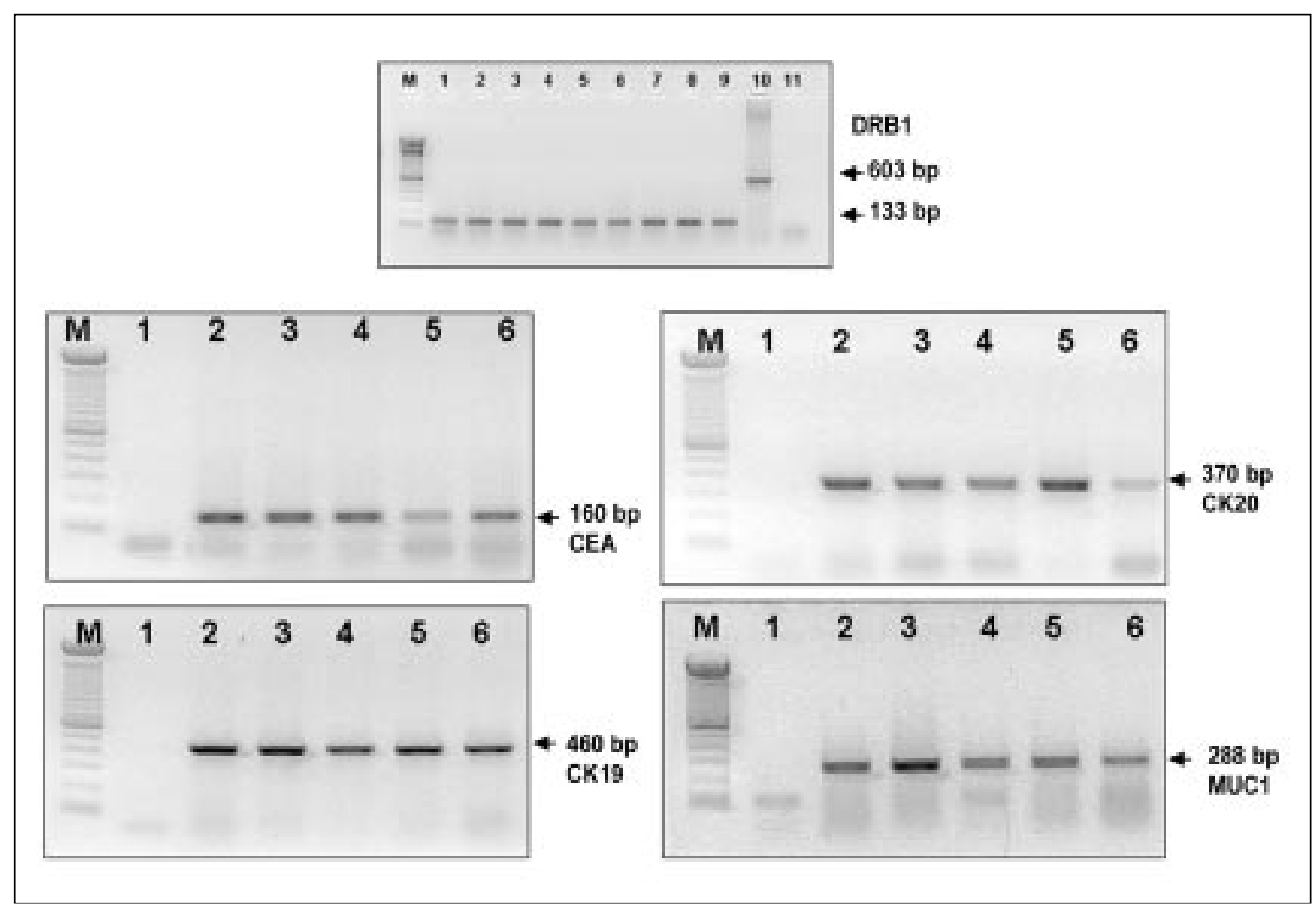

FIGURA 1. Geles de agarosa mostrando los productos de amplificación mediante RT-PCR de los ARNm de los genes DRB1, CEA, MUC1, CK19 y CK20. 100 pb. Marcador de ADN de 100 pb. Línea 1=control negativo, Línea 2=control positivo, líneas 3-6 muestras de médula ósea. En el gel de DRB1 las líneas 1-9 Muestras de médula ósea con amplificación sólo de ARN (133 pb) y con ADN (línea 10) (603 BP). Línea 11 control negativo. 
respecto de los tumores frescos congelados y sensibilidad de los genes en las muestras de médula ósea. Para el cálculo de sobreviva se construyeron curvas de Kaplan Meier. Los resultados fueron considerados estadísticamente significativos con un $\mathrm{p} \varangle 0,05$.

\section{RESULTADOS}

Las características generales del grupo estudiado se observan en la Tabla 2. El promedio de edad de los 48 pacientes con cáncer de vesícula biliar fue de 57,5 años con rango de 35-77 años. La muestra incluyó sólo 6 hombres (12,5\%). En su mayoría correspondió a tumores avanzados (96\% de tumores subserosos o serosos) histológicamente moderados o poco diferenciados ( $96 \%$ en conjunto).

Las 68 muestras correspondientes a 38 aspirados de médula ósea, 10 tumores de vesícula biliar congelados y 20 muestras provenientes de donantes aparentemente sanos, fueron analizadas para la detección de la expresión génica de los genes CEA, CK19, CK20 y MUC1. Todas las muestras estudiadas mostraron calidad y pureza del ADNc mediante amplificación de DRB1.

La Tabla 3 muestra los resultados de pacientes con cáncer, donantes y tumores congelados. La expresión de MUC1, CK19, CEA y CK20 en los aspirados de médula ósea fue de 23 (60,5\%), 12 $(31,6 \%), 3(7,9 \%)$ y $3(7,9 \%)$, respectivamente. Sin considerar los resultados de MUC1, 37\% (14/ $38), 13 \%(5 / 38)$ y $5 \%$ (2/38) fueron positivos para 1,2 y 3 genes, respectivamente.

Las muestras congeladas de los cánceres vesiculares fueron todas positivas para CEA, CK19, y MUC1. Siete de los 10 fueron positivos para CK20 ARNm y todas las muestras reunidas de los 20 donantes fueron negativos para CEA, sólo un control fue positivo para ARNm de ambas citoque-
Tabla 2. Características generales de los tumores de vesícula biliar estudiados $(n=48)$ (38 muestras de médula ósea +10 tumores congelados)

$\begin{array}{lr}\text { Género } & \\ \text { Femenino } & 42 / 48 \\ \text { Masculino } & 6 / 48 \\ \text { Edad } & \\ \quad \text { Promedio } & 57,5 \\ \quad \text { Rango (años) } & 35-77 \\ \text { Grado de diferenciación } & \\ \quad \text { Bien } & 2(4 \%) \\ \text { Moderado } & 23(48 \%) \\ \text { Poco } & 23(48 \%) \\ & 48 \\ \text { Nivel de infiltración } & \\ \text { Túnica muscular } & 2(4 \%) \\ \text { Subserosa } & 16(33 \%) \\ \text { Serosa } & 30(63 \%) \\ & 48 \\ \text { Estadio } & \\ \text { Incipiente } & 2(4 \%) \\ \text { Avanzado } & 46(96 \%) \\ & 48 \\ \text { Diseminación extravesicular } & \\ \text { Positiva } & 13(26 \%) \\ \text { Negativa } & 18(38 \%) \\ \text { No evaluado } & 17(36 \%) \\ & 48\end{array}$

ratinas, CK19 y CK20. Sin embargo, 17 de los 20 donantes fueron positivos para MUC1. En relación con los tumores frescos congelados la sensibilidad de las mediciones de expresión génica CK19, CEA y MUC fue de $100 \%$ y para CK20 de $70 \%$, sin embargo la especificidad de la medición en la expresión génica de MUC1 fue sólo de 15\% en comparación con el 95\% de CK19 y CK20 y del $100 \%$ mostrado por CEA. Debido a la baja especi-

Tabla 3. Expresión génica de los diferentes genes en los diferentes tipos de muestras

\begin{tabular}{|lrrrrr|}
\hline Tipo de muestra & $\mathrm{n}$ & CK-19 & CK-20 & CEA & MUC1 \\
\hline a) Tumores congelados & 10 & 10 & 7 & 10 & 10 \\
b) Donantes de banco de sangre & 20 & 1 & 1 & 0 & 17 \\
c) Aspirado de médula ósea & 38 & 12 & 3 & 3 & 23 \\
\hline
\end{tabular}


ficidad de MUC1, sus resultados no fueron considerados para su análisis en este manuscrito. En la Tabla 4 se muestra el detalle de los valores de sensibilidad, en muestras de médula ósea sólo considera a pacientes con enfermedad diseminada, ya que no es posible asegurar que hubiese sido posible detectar tumor en pacientes sometidos a cirugías potencialmente curativas y los valores de especificidad para cada gen se obtuvieron en relación con los donantes.

Doce de las 38 (27,4\%) muestras de sangre de los pacientes con cáncer fueron positivas para uno de los tres genes estudiados. En aquellos donde la médula ósea fue positiva para los tres genes (2/38), todos se encontraban en un estado metastásico avanzado.

Analizamos separadamente grupos de pacientes con pronóstico diferente, basado en factores tales como el nivel de infiltración de la pared o presencia de metástasis (Tabla 5). De los 8 pacientes con aparente buen pronóstico, se observó expresión de los genes estudiados en 2 pacientes, lo que corresponde a $25 \%$, de este grupo. Uno tenía un compromiso restringido a la túnica muscular, mientras el otro paciente había sido sometido a una reoperación. Sin embargo, los ganglios linfáticos y el hígado se encontraban sin tumor. Por otro lado, entre los 13 pacientes con enfermedad avanzada, metástasis hepática 0 diseminación duodenal, se encontró micrometástasis en 5 pacientes (38\%) (Tabla 6). Dos pacientes de este grupo que resultaron negativos para los genes estudiados, fueron tratados previo a la toma de muestra con Gemcitabina.

El promedio del seguimiento de este grupo fue de 12 meses, nosotros no hemos, hasta ahora, encontrado diferencia de sobrevida en el grupo estudiado.

Tabla 4. Valores de sensibilidad y especificidad de los genes estudiados

\begin{tabular}{|lrrrr|}
\hline & CK19 & CK20 & CEA & MUC1 \\
\hline Sensibilidad tejidos congelados (a-b) & $100 \%$ & $70 \%$ & $100 \%$ & $100 \%$ \\
Sensibilidad médula ósea (b-c) & $40 \%$ & $13 \%$ & $13 \%$ & $76 \%$ \\
Especificidad (a-b) & $95 \%$ & $95 \%$ & $100 \%$ & $15 \%$ \\
\hline
\end{tabular}

$\mathrm{a}=$ tumores congelados; $\mathrm{b}=$ donantes; $\mathrm{c}=$ médula ósea

Tabla 5. Expresión de génica de los genes en estudio en muestras de médula ósea de 8 casos potencialmente curativos

\begin{tabular}{|lcccccc|}
\hline Iniciales & $\begin{array}{c}\text { Nivel de } \\
\text { infiltración }\end{array}$ & $\begin{array}{c}\text { Disección } \\
\text { ganglionar }\end{array}$ & $\begin{array}{c}\text { Compromiso } \\
\text { hepático }\end{array}$ & CK19 & CK20 & CEA \\
\hline RL & SS & - & - & - & - & - \\
SS & SS & - & - & - & - & - \\
LC & SS & - & - & - & - & - \\
FO & SE & - & - & - & - & - \\
AM & SS & - & - & + & - & - \\
LC & TM & Sin cirugía secundaria & + & - & - \\
NI & SS & Sin cirugía secundaria & - & - & - \\
SA & TM & Sin cirugía secundaria & - & - & - \\
\hline
\end{tabular}

$\mathrm{TM}=$ Túnica muscular SS= subserosa; $\mathrm{SE}=$ serosa 
Tabla 6. Expresión génica en muestras de médula ósea de 13 casos con diseminación extravesicular (resecciones no curativas)

\begin{tabular}{|clccc|}
\hline Iniciales & Tumores avanzados & CK19 & CK20 & CEA \\
\hline AR & Metástasis hepática & - & - & - \\
MC & Metástasis hepática & - & - & - \\
RC & Metástasis hepática & - & - & + \\
CB & Diseminación duodenal & - & - & $*$ \\
FE & Metástasis hepática & - & - & - \\
HU & Metástasis hepática & - & - & - \\
EA & Metástasis hepática & - & - & $*$ \\
MM & Metástasis hepática & + & + & + \\
TLI & Metástasis hepática & - & - & - \\
NS & Metástasis hepática & + & - & - \\
MH & Metástasis hepática & + & - & - \\
MG & Metástasis hepática & - & - & - \\
MA & Infiltración hepática & + & - & \\
\hline
\end{tabular}

* Pacientes tratados con Gemcitabina previos a la toma de muestra de médula ósea.

\section{DisCUSIÓN}

En este estudio analizamos cuatro diferentes marcadores (MUC1, CEA, CK19, y CK20 mARN), con el objetivo de determinar los límites que estos cuatro test ofrecen para la detección de células de cáncer de vesícula biliar y si la presencia de transcriptos de ARN epitelial en los aspirados de médula ósea de los pacientes con cáncer de vesícula biliar se correlaciona con características clínico patológicas.

MUC 1 (Mucina sialada 1). Corresponde a una glicoproteína de transmembrana con un gran dominio extracelular, que se expresa en el fenotipo metastático $26-28$. En el cáncer de la vesícula biliar, la expresión de la mucina sialada 1 (MUC1), en el estroma que rodea a las glándulas tumorales puede ser reconocido mediante un nuevo anticuerpo mAb, MY. 1E12 29 . La expresión de este antígeno se asocia con una mayor agresividad y con peor pronóstico ${ }^{30,31}$. En el presente trabajo los transcriptos de ARN de MUC1 fueron positivos en 23 de los 38 aspirados de médula ósea, pero también fueron positivos en 17 de los 20 donantes (especificidad de 15\%). Aparentemente podría haber una reacción cruzada con la expresión de otros genes expresados en médula ósea o simple- mente MUC1 es expresado en la médula ósea de individuos normales. Dent et al concluyó en $1999^{32}$ que MUC1 es expresado en forma extensa en los tejidos hematopoyéticos $\mathrm{y}$, por lo tanto, no es recomendable como un marcador de micrometástasis epiteliales. Debido a estas consideraciones los resultados de MUC1 no serán consideradas en esta sección.

Antígeno carcinoembrionario (CEA). Es una glicoproteína que es normalmente expresada en ciertas partes del cuerpo y comúnmente sobreexpresada en la mayoría de los carcinomas del colón, recto, mama, pulmón y páncreas y del tracto gastrointestinal. Una expresión aumentada del antígeno carcinoembrionario promueve una mayor adhesión intercelular, lo cual favorece la aparición de metástasis ${ }^{33}$. Actualmente el CEA es ampliamente usado como un marcador tumoral para la detección molecular de células tumorales gastrointestinales y de cáncer de mama ${ }^{3,34}$. Encontramos expresión en $100 \%$ de los tumores analizados. Debido a esto debiese ser considerado un buen marcador para la búsqueda de células tumorales en sangre periférica y médula ósea. En nuestro estudio sólo 3 de 38 casos (equivalente a 7,9\% de los pacientes) con cáncer de vesícula biliar mostró expresión de transcrip- 
tos de CEA. Los tres pacientes en los cuales el CEA fue detectado tenían una enfermedad avanzada. Mory et al han demostrado que la amplificación mediante RT-PCR de los transcriptos de CEA son un medio eficiente en la detección de células circulantes de tumores sólidos en sangre periférica y que incluso en los cánceres gastrointestinales se debiese considerar como un indicador de enfermedad sistémica, aun cuando haya sido catalogado como incipiente ${ }^{3}$.

Citoqueratinas (CK19 y CK20). Las citoqueratinas comprenden una familia de multigenes de 20 polipéptidos relacionados (CK1-CK20). Codifican los constituyentes de los filamentos intermedios de las zonas epiteliales que son expresados en varias combinaciones, dependiendo del tipo epitelial y el grado de diferenciación. Particularmente la CK19 y la CK20 muestran un perfil muy restringido de expresión tisular y han sido exitosamente usados para la detección de células circulantes tumorales en sangre de pacientes con cáncer de mama, cáncer pulmonar y carcinomas gastrointestinales 3,25,35,36.

En nuestro estudio encontramos una expresión de transcriptos de CK19 en 13/38 (34\%) de las muestras y para CK20 en 3/38 (8\%) de las muestras. En nuestro estudio 5 de 13 de los pacientes con enfermedad masiva diseminada, es decir, metástasis hepática, presentaron positividad para la expresión de al menos uno de los 3 genes estudiados (CEA, CK19 y CK20).

Estos hallazgos indican que la detección molecular de CEA, CK19 y CK20 en los aspirados de médula ósea puede tener un valor pronóstico para pacientes con carcinoma de vesícula biliar.

Los protocolos basados en PCR aumentan la sensibilidad de la detección de células tumorales en circulación de 1-10 células tumorales en 10 millones de células normales, debemos hacer notar además la especificidad por la casi ausente expresión ya sea de CK19 o CK20 en las muestras obtenidas de los 20 donantes, aparentemente normales de nuestro estudio, alcanzando una especificidad de 95\% para CK19 y CK20. El único caso que presentó positividad para
CK19 y CK20, lo hizo en forma simultánea en un donante y no hemos podido hasta ahora lograr ubicar a ese individuo para verificar su actual estado de salud.

Sin embargo, no podemos tampoco dejar de mencionar que algunos reportes han demostrado que la CK19 y la CK20, son expresados en muestras sanguíneas de individuos sanos y algunos investigadores demostraron que las diferencias en la sensibilidad de los ensayos y en la forma de tomar la muestra podrían producir estas diferencias ${ }^{37,38}$.

Esto demuestra que los resultados falsos negativos pueden ser debido a un bajo nivel de expresión en el gen, que se está buscando a pequeñas cantidades de células tumorales o a la presencia de clones poco diferenciados que no expresan los marcadores titulares específicos que están siendo analizados. Por esta razón, es más posible que una correlación positiva se pueda observar al analizar más de un gen a la vez, de manera de minimizar la aparición de falsos negativos.

Del mismo modo el discontinuo desprendimiento de células tumorales hacia la circulación puede también resultar en falsos negativos, dependiendo del momento en que la muestra es analizada $^{39,40}$. Estos problemas deben ser minimizados por el uso de múltiples marcadores y análisis de sangre y de médula ósea en diferentes tiempos.

En conclusión, aunque el número total de pacientes es pequeño para obtener conclusiones definitivas, la determinación de CEA, CK19 y CK20 mediante RT-PCR podría convertirse en una herramienta poderosa para la detección de micrometástasis de carcinoma de vesícula biliar en los aspirados de médula ósea, que permita guiar en forma racional el tratamiento y predecir en forma oportuna el pronóstico de los pacientes. El foco de este estudio debiese ser el análisis de pacientes con buen pronóstico, con el objetivo de detectar aquellos en los cuales la diseminación puede ser precedida o diagnóstica en etapas iniciales. Para lograr este objetivo el estudio de una serie de mayor tamaño, que incluya mayor cantidad de pacientes potencialmente curativos, debe ser analizado. 


\section{REFERENCIAS}

1. Medina E, KAEMPFFER AM. Mortalidad del Adulto en Chile. Rev Méd Chile 2000; 128: 1144-9.

2. MEDINA E, KAEMPFFER AM. Mortalidad por cáncer en Chile: Consideraciones epidemiológicas. Rev Méd Chile 2001; 129: 1195-202.

3. Аваті A, LотTA LA. Looking forward in diagnostic pathology: the molecular superhighway. Cancer 1996; 78: 1-3.

4. Pelkey TJ, Frierson HF Jr, Bruns DE. Molecular and immunological detection of circulating tumor cells and micrometastases from solid tumors. Clin Chem 1996; 42: 1369-81.

5. Mori M, Mimori K, Ueo H et al. Molecular detection of circulating solid carcinoma cells in the peripheral blood: the concept of early systemic disease. Int J Cancer 1996; 68: 739-43.

6. NaKamori S, Kameyama M, Furukawa $\mathrm{H}$ et aL. Genetic detection of colorectal cancer cells in circulation and lymph nodes. Dis Colon Rectum 1997; 40: S29-36.

7. Min CJ, TAFRA L, Verbanac KM. Identification of superior markers for polymerase chain reaction detection of breast cancer metastases in sentinel lymph nodes. Cancer Res 1998; 58: 4581-4.

8. Watson MA, DinTZis S, Darrow CM ET al. Mammaglobin expression in primary, metastatic, and occult breast cancer. Cancer Res 1999; 59: 302831.

9. Hoon DS, Wang Y, Daie PS et al. Detection of occult melanoma cells in blood with a multiplemarker polymerase chain reaction assay. J Clin Oncol 1995; 13: 2109-16.

10. Hayashi N, Ito I, Yanagisana A et al. Genetic diagnosis of lymph-node metastasis in colorectal cancer. Lancet 1995; 345: 1257-9.

11. Demeure MJ, Doffek KM, Komorowski RA, WiLson SD. Adenocarcinoma of the pancreas: detection of occult metastases in regional lymph nodes by a polymerase chain reaction-based assay. Cancer 1998; 83: 1328-34.

12. Deguchi $T$, Doi $T$, Ehara $H$ et al. Detection of micrometastatic prostate cancer cells in lymph nodes by reverse transcriptase-polymerase chain reaction. Cancer Res 1993; 53: 5350-4.

13. Lehrer S, Terk M, Piccol SP, Song HK, Lavagnini P, LUDERER AA. Reverse transcriptase-polymerase chain reaction for prostate-specific antigen may be a prognostic indicator in breast cancer. $\mathrm{Br} \mathrm{J}$ Cancer 1996; 74: 871-3.

14. Timar J, Csuka O, Orosz Z, Jeney A, Kopper L Molecular pathology of tumor metastasis. II. Molecular staging and differential diagnosis. Pathol Oncol Res 2002; 8: 204-19.

15. Liefers GJ, Cleton-Jansen AM, van de Velde CJ et AL. Micrometastases and survival in stage II colorectal cancer. N Engl J Med 1998; 339: 2238.

16. Osaki T, Oyama T, Gu CD et al. Prognostic impact of micrometastatic tumor cells in the lymph nodes and bone marrow of patients with completely resected stage I non-small-cell lung cancer. J Clin Oncol 2002; 20: 2930-6.

17. Sugio K, Kase S, Sakada T et al. Micrometastasis in the bone marrow of patients with lung cancer associated with a reduced expression of $\mathrm{E}$ cadherin and beta-catenin: risk assessment by immunohistochemistry. Surgery 2002; 131: S22631.

18. Schleiermacher G, Peter M, Oberun O et al. Increased risk of systemic relapses associated with bone marrow micrometastasis and circulating tumor cells in localized ewing tumor. J Clin Oncol 2003; 21: 85-91.

19. Jung YS, LeE KJ, Kim HJ et AL. Clinical significance of bone marrow micrometastasis detected by nested rt-PCR for keratin-19 in breast cancer patients. Jpn J Clin Oncol 2003; 33: 167-72.

20. JiaO X, KRASNa MJ. Clinical significance of micrometastasis in lung and esophageal cancer: a new paradigm in thoracic oncology. Ann Thorac Surg 2002; 74: 278-84.

21. The new TNM classification in Gastroenterology (1997). Endoscopy 1998; 30: 643-9.

22. Сномczynski P, SAcchi N. Single-step method of RNA isolation by acid guanidinium thiocyanatephenol-chloroform extraction. Anal Biochem 1987; 162: 156-9.

23. Bostick PJ, Hoon DS, Cote RJ. Detection of carcinoembryonic antigen messenger RNA in lymph nodes from patients with colorectal cancer. N Engl J Med 1998; 339: 1643-4.

24. Huang P, Wang J, Guo Y, Xie W. Molecular detection of disseminated tumor cells in the peripheral blood in patients with gastrointestinal cancer. J Cancer Res Clin Oncol 2003; 129: 192-8. 
25. de AretXabala X, Roa I, Burgos L Gallbladder cancer, management of early tumors. Hepatogastroenterology 1999; 46: 1547-51.

26. HiLkens J, Ligtenberg MJ, Vos HL, Litvinov SV. Cell membrane-associated mucins and their adhesionmodulating property. Trends Biochem Sci 1992; 17: 359-63.

27. Gendier SJ, Lancaster CA, Taylor-Papadimitriou J et AL. Molecular cloning and expression of human tumor-associated polymorphic epithelial mucin. J Biol Chem 1990; 265: 15286-93.

28. Nakamori S, Ota DM, Cleary KR, Shirotani K, IRIMURA T. MUC1 mucin expression as a marker of progression and metastasis of human colorectal carcinoma. Gastroenterology 1994; 106: 353-61.

29. Yamamoto M, Bhavanandan VP, NAKamori S, IrimuRa T. A novel monoclonal antibody specific for sialylated MUC1 mucin. Jpn J Cancer Res 1996; 87: 488-96.

30. Kawamoto T, Shoda J, Asano T et al. Expression of cyclooxygenase-2 in the subserosal layer correlates with postsurgical prognosis of pathological tumor stage 2 carcinoma of the gallbladder. Int J Cancer 2002; 98: 427-34.

31. Kashiwagi H, Kijima H, Dowaki S et al. MUC1 and MUC2 expression in human gallbladder carcinoma: a clinicopathological study and relationship with prognosis. Oncol Rep 2001; 8: 485-9.

32. Dent GA, Civalier CJ, Brecher ME, Bentley SA. MUC1 expression in hematopoietic tissues. Am J Clin Pathol 1999; 111: 741-7.
33. Marshall J. Carcinoembryonic antigen-based vaccines. Semin Oncol 2003; 30: 30-6.

34. Gerhard M, Juhl H, Kalthoff H, Schreiber HW, Wagener C, Neumaier M. Specific detection of carcinoembryonic antigen-expressing tumor cells in bone marrow aspirates by polymerase chain reaction. J Clin Oncol 1994; 12: 7259.

35. PeCK K, Sher YP, Shih JY, Roffler SR, Wu CW, YANG PC. Detection and quantitation of circulating cancer cells in the peripheral blood of lung cancer patients. Cancer Res 1998; 58: 2761-5.

36. Denis MG, Lipart C, Leborgne J et al. Detection of disseminated tumor cells in peripheral blood of colorectal cancer patients. Int J Cancer 1997; 74: 540-4.

37. Champelovier P, Mongeiard F, Seigneurin D. CK20 gene expression: technical limits for the detection of circulating tumor cells. Anticancer Res 1999; 19: 2073-8.

38. Viems F, Soong R, DiePSTRA H et al. Effect of blood sample handling and reverse transcriptase-polymerase chain reaction assay sensitivity on detection of CK20 expression in healthy donor blood. Diagn Mol Pathol 2002; 11: 90-7.

39. Glaves D, Huben RP, Weiss L. Haematogenous dissemination of cells from human renal adenocarcinomas. Br J Cancer 1988; 57: 32-5.

40. Ghossein RA, Bhattacharya S. Molecular detection and characterization of circulating tumour cells and micrometastases in solid tumours. Eur J Cancer 2000; 36: 1681-94. 